\title{
EDITORIAL
}

\section{REFACS: a evolução de um periódico científico}

Em 2018, a Revista Família, Ciclos de Vida e Saúde no Contexto Social (REFACS) estará em seu sexto ano de publicação e, desde o seu primeiro número, ocorrida em 2013, vem buscando se expandir e adaptar às boas práticas e novas tendências editorais do mercado, se caracterizando como interdisciplinar em saúde.

A REFACS é um dos periódicos da Universidade Federal do Triângulo Mineiro, com publicação trilíngue (português, inglês e espanhol) e vinculada ao Programa de Residência Integrada e Multiprofissional em Saúde (RIMS) e ao Grupo de Pesquisa do CNPq, Ciclos de Vida, Família e Saúde no Contexto Social (CIFACS). Dentre os 17 volumes publicados até o momento, contamos com uma soma de 159 artigos, dentre eles produções oriundas de pesquisa original, revisões, estudos de caso, reflexões, relatos de experiência e editoriais. A revista trabalha com fluxo de avaliação por pares e a cegas, respeitando a ética editorial, através da colaboração de 40 consultores internacionais, regionais e locais, de diversas áreas de especialidade e facetas profissionais.

Este periódico está indexado em 10 bases de dados, internacionais e nacionais, trabalhando com a política de acesso aberto e gratuito a toda a comunidade, e está sempre buscando a melhora de sua indexação em bases conhecidas e renomadas, para melhor contribuir ao campo científico. A partir do ano de 2015, as publicações passaram a contar com a vinculação do Digital Object Identifier (DOI), que consiste num código alfanumérico único que identifica o artigo publicado por meio digital para que ele não se perca na web, mesmo que sua localização ou metadados sejam modificados.

Os desafios contemporâneos vivenciados pelo Brasil (economia, política, e outros) associados à forte expansão tecnológica exigem a adoção de estratégias e proposições inovadoras, de forma a conseguir se manter num mercado cada vez mais competitivo e seletivo, e responder de forma eficaz e eficiente as demandas sociais que são colocadas ao mundo acadêmico ${ }^{1}$. 0 exponencial crescimento propiciado pelo desenvolvimento tecnológico muito facilita o acesso à informação, permitindo que os resultados de pesquisa estejam disponibilizados de forma fácil e rápida².

Neste contexto, com vistas a se expandir e se posicionar no mercado a REFACS tem buscado, através de seu Comitê Gestor, adotar as melhores práticas editorais e age veementemente na redução de más condutas do campo editorial que emergem na atualidade como: autoplágio, publicação duplicada, publicação redundante, falsificação ou fabricação de dados, manipulação de imagens, impactos ao bem-estar humano ou animal, conflito de interesses, e outros ${ }^{1}$.

Em 2017, segundo dados da Coordenação de Aperfeiçoamento de Pessoal de Nível Superior ${ }^{3}$ (CAPES) por intermédio da avaliação quadrienal de 2013 a 2016, a REFACS passou pelo seu primeiro processo de avaliação por este órgão, recebendo as qualificações para as seguintes áreas: B3 - Psicologia e Serviço Social; B4 - Educação Física, Enfermagem, Interdisciplinar, Odontologia e Saúde Coletiva; B5 - Medicina II e C - Ciências Biológicas e Educação. Apesar de ser uma avaliação para nós muito satisfatória temos trabalhado incessantemente de forma a melhorar nossos indicadores, sempre se adequando as inovações e tendências do mercado editorial.

Sendo assim, a partir de 2018 a REFACS passa a aumentar o número de publicações por volume (de 10 para 15 artigos), para acompanhar a evolução que vem ocorrendo, sempre buscando a excelência contínua de modo que a pesquisa e outras produções impacte de maneira positiva na vida dos indivíduos e da sociedade.

\section{REFERÊNCIAS}

Boa leitura,

1. Nassi-Calò L. Evaluation metrics in science: current status and prospects. Rev Latino-Am. Enfermagem [Internet]. 2017 [citado em 28 mar 2017]; 25:e2865. DOI: http://dx.doi.org/10.1590/1518-8345.0000.2865

2. Padilha MICS. Historicity of the ways in which knowledge production impacts practice. Rev Latino-Am. Enfermagem [Internet]. 2017 [citado em 28 mar 2017]; 25:e2867. DOI: http://dx.doi.org/10.1590/1518-8345.0000.2867

3. Coordenação de Aperfeiçoamento de Pessoal de Nível Superior (CAPES). Classificação de Periódicos Quadriênio 2013 2016 [página de internet]. 2017 [citado em 28 mar 2017]. Disponível em: https://sucupira.capes.gov.br/sucupira/public/index.jsf

Luan Augusto Alves Garcia

Enfermeiro. Mestre em Atenção à Saúde. Doutorando do Programa de Pós-Graduação Stricto Sensu em Atenção à Saúde (PPGAS) da Universidade Federal do Triângulo Mineiro (UFTM). Comissão de Fluxo e Editoração Científica da REFACS.

Giovanna Gaudenci Nardelli

Enfermeira. Mestre em Atenção à Saúde. Doutoranda do PPGAS da UFTM. Comissão de Tradução, Editoração Científica e Diagramação da REFACS. 